\title{
PEGylation of Lumbrokinase improves pharmacokinetic profile and enhances anti-thrombotic effect in a rat carotid artery thrombosis model
}

\author{
MINGJI JIN ${ }^{1,2 *}$, GUANGMING JIN ${ }^{3 *}$, WEI HUANG ${ }^{1,2}$ and ZHONGGAO GAO ${ }^{1,2}$ \\ ${ }^{1}$ State Key Laboratory of Bioactive Substance and Function of Natural Medicines; ${ }^{2}$ Department of Pharmaceutics, \\ Institute of Materia Medica, Chinese Academy of Medical Sciences and Peking Union Medical College, Beijing 100050; \\ ${ }^{3}$ Department of Diagnostic Radiology 2, Yanbian University Hospital, Yanji, Jilin 133000, P.R. China
}

Received March 18, 2017; Accepted July 28, 2017

DOI: $10.3892 / \mathrm{mmr} .2017 .7171$

\begin{abstract}
The present study aimed to prepare injectable Lumbrokinase (LK) with long circulation time in addition to enhanced anti-thrombotic efficacy. Following preparation, the pharmacokinetic and anti-thrombotic effect of the drug in a rat carotid artery thrombosis model was evaluated. The drug was prepared by conjugation of $\mathrm{LK}$ with $\mathrm{mPEG}-\mathrm{SC}_{20000}$ as previously reported. The pharmacokinetics of the mPEG-SC $20000-\mathrm{LK}$ were then examined and the anti-thrombotic activity in an artery-vein bypass thrombosis rat model was evaluated. Finally, the parameters of fibrinolysis including thromboxane $\mathrm{B} 2$, prostaglandin $\mathrm{F}_{1 \alpha}$, tissue plasminogen activator and plasminogen activator inhibitor-1 were compared between native LK and $\mathrm{mPEG}-\mathrm{SC}_{20000}$ - $\mathrm{LK}$ in a $\mathrm{FeCl}_{3}$-induced carotid artery thrombosis rat model. $\mathrm{mPEG}-\mathrm{SC}_{20000}-\mathrm{LK}$ was successfully prepared by PEGylation of $\mathrm{LK}$ with $\mathrm{mPEG}_{20000}-\mathrm{SC}$ in optimal conditions. Pharmacokinetic analysis demonstrated that the biological half-life of the $\mathrm{mPEG}_{20000}-\mathrm{SC}-\mathrm{LK}$ increased by 2.2-fold compared with native LK. In vivo anti-thrombotic analysis indicated that $\mathrm{mPEG}_{20000}-\mathrm{SC}-\mathrm{LK}$ exhibited a greater anti-thrombotic effect in artery-vein bypass thrombosis and $\mathrm{FeCl}_{3}$-induced carotid artery thrombosis models compared with native LK. In conclusion, injectable PEGylated LK with prolonged half-life and enhanced anti-thrombotic effect is a potential anti-thrombotic agent for long-acting treatment of the thrombus diseases.
\end{abstract}

Correspondence to: Dr Zhonggao Gao, State Key Laboratory of Bioactive Substance and Function of Natural Medicines, Institute of Materia Medica, Chinese Academy of Medical Sciences and Peking Union Medical College, 1 Xiannongtan Street, Beijing 100050, P.R. China

E-mail: zggao@imm.ac.cn

${ }^{*}$ Contributed equally

Key words: Lumbrokinase, PEGylation, thrombolytic activity, long-acting

\section{Introduction}

Thrombotic disease is a common multiple disease that imperils people's life. The formation of thrombosis is a key event in the pathogenesis of myocardial infarction, stroke, and other ischemia conditions that comprise the most common and growing causes of morbidity and mortality (1). LK consists of a group of serine proteases with strong fibrinolytic activity $(2,3)$, can dissolve fibrin either directly or indirectly by activating profibrinolysin. LK has been widely used as a novel, orally administered drug for thrombotic diseases and has caused growing interest in East Asia (4). Although some thrombolytic agents such as urokinase (uPA), streptokinase (SK) and tissue plasminogen activator (t-PA) are all typically used to dissolve clots, they are not specific to fibrin and have severe side effects such as heavy blood loss $(5,6)$. In contrast, $\mathrm{LK}$ is very specific to fibrin as a substrate and does not cause excessive bleeding (7). Furthermore, some researches had shown that LK contained several active components $(8,9)$ which could dissolve the fibrin directly or can convert plasminogen to plasmin by inducing endogenous t-PA activity to dissolve fibrin clots (10). However, The LK is an oral drug which belongs to biological products with very short half-life, it needs oral 2-3 times a day. And more importantly, given the fact that thrombotic disease is an acute illness, oral administration of the drug can not serve as first choice because of its low bioavailability and slow absorption in human body. In order to solve this problem, we have prepared it into intravenous agents by PEG modification which could improve its half-life, reduce dosing frequency. According to the results of the pharmacokinetics, the ideal result is that the drug can maintain for 12 to $24 \mathrm{~h}$ in the body after intravenous injection.

The attachment of proteins to polymers, especially to polyethylene glycol (PEG), is an established technique to enhance the therapeutic and biotechnological potential of numerous proteins, macromolecular carriers, oligonucleotides, and some biomolecules (11). PEGylation can increase the size and molecular weight of conjugated biomolecules and improve their pharmacokinetics. At the same time, it can protect the drug from enzymatic degradation, reduce renal clearance as well as inhance pharmacological activity in vivo (12-14). 
The covalent conjugation of PEG to therapeutic proteins is a clinically successful strategy for extending serum half-life to reduce administration frequency (15-17). Many biochemical agents such as tPA (18), SK (19), uPA (20), and staphylokinase (Sak) $(21,22)$ have been modified with PEG as prodrugs for preparing injective formulation and for prolonging half-life. Currently, there are at least 10 PEGylated products with FDA marketing approval, and numerous other conjugates are entering clinical trials $(23,24)$.

In our previous study, we investigated the optimal PEGylation condition with buffer $\mathrm{pH}$ of 8.0, reaction time of $5 \mathrm{~h}$, reaction temperature of $0^{\circ} \mathrm{C}$ and molar ratio of $1: 25$. The primary amino group of $\mathrm{LK}$ and functional group of $\mathrm{mPEG}$ react under the buffer solution system, and finally generate PEGylated LK (Fig. 1). The in vitro fibrinolytic activity of both native and PEGylated LK was measured in comparison to that of uPA on fibrin plates. The results showed that $\mathrm{mPEG}_{20000}$-SC-LK was prepared successfully and had strong fibrinolytic activity in vitro. In this study, conjugation of LK with $\mathrm{mPEG}-\mathrm{SC}_{20000}$ was prepared and analyzed as previously reported (25). Then, we studied the pharmacokinetics and in vivo anti-thrombosis efficacy of $\mathrm{mPEG}_{20000}-\mathrm{SC}-\mathrm{LK}$ with rat carotid artery thrombosis model. This is the first systematic report to evaluate the anti-thrombotic effect of PEGylated injection form of LK in animal model.

\section{Materials and methods}

Materials and animals. LK (molecular weight of $24 \mathrm{KDa}$ ) was purchased from Shanghai Guoyuan Biotech Co., Ltd. mPEG-SC ${ }_{20000}$ was purchased from JenKem Technology (Beijing, China). An SDS-PAGE test kit was obtained from Beijing CellChip Biotechnology Co., Ltd., and SDS-PAGE protein standards were purchased from Bio-Rad (Hercules, CA, USA). Rat Lumbrokinase ELISA kit was purchased from Shanghai Enzyme-linked Biotechnology Co., Ltd. Cyano-4-hydroxycinnamic acid (CHCA) and trifluoroacetic acid (TFA) were from Sigma-Aldrich (St. Louis, MO, USA). The standard substances used in this study were all purchased from National Institutes for Food and Drug Control. All other reagents and chemicals were of analytical grade and used as received. Male Sprague-Dawley (SD) rats were purchased from Beijing Vital River Laboratories (Beijing, China). All animal experiments were approved by the Laboratory Animal Ethics Committee at the Institute of Materia Medica at Peking Union Medical College. All procedures conformed with institutional guidelines and protocols for the care and use of laboratory animals with the Certification number of 2012/0001/SCXK for animal experiments.

Preparation of the PEGylated LK. For the synthesis of the $\mathrm{mPEG}_{20000}$-SC-LK (Fig. 1), the PEGylation was prepared as previously reported (25). Firstly, crude LK was purified using superdex $75(1.6 \times 25 \mathrm{~cm}$, GE Healthcare) and Hi Trap DEAE FF column (GE Healthcare, Chicago, IL, USA) by Akta Purify 10 system. The purified LK and mPEG-SC 20000 were then mixed at molar ratio of 1:25, added $50 \mathrm{mM}$ PBS ( $\mathrm{pH} 8.0)$ at $0^{\circ} \mathrm{C}$, reacted for $5 \mathrm{~h}$. Finally, the reaction was terminated by adding $11 \mathrm{mg} / \mathrm{ml}$ glycine. The reaction mixture was subjected to superdex 75 column for removal of the free PEG reagent.
Starting materials and PEGylated products were examined by HPLC to calculate the extent of PEGylation according to the following equation:

Extent of PEGylation $(\%)=(1-$ residual peak area of LK after modification/peak area of LK before modification) $\mathrm{x} 100 \%$.

Analytical methods. Molecular weight of $\mathrm{mPEG}_{20000}$-SC-LK was measured using a MALDI-TOF-MS 4800 Plus (ABI; Thermo Fisher Scientific, Waltham, MA, USA) $(14,26)$. Sample and matrix solution (CHCA in $70 \%$ of acetonitrile/methanol with $1 \%$ TFA) was mixed together, spotted onto a well of the sample plate and dried. The positive ion TOF detection was performed by using an accelerating voltage of $25 \mathrm{kV}$. SDS-PAGE was carried out as described by Park (26), the protein concentration was determined by Bradford assay (Bio-Rad). Native LK, purified LK and $\mathrm{mPEG}_{20000}-\mathrm{SC}-\mathrm{LK}$ were analyzed by SDS-PAGE using $10 \%$ polyacrylamide gradient gel with standard proteins as markers. Gels were stained with coomassie blue, and then analyzed using a gel imaging system (BIO-BEST 135A; SIM International Group Co., Ltd., Los Angeles, CA, USA). The in vitro fibrinolytic activity of both purified LK and $\mathrm{mPEG}_{20000}-\mathrm{SC}-\mathrm{LK}$ were measured using the method of Asturp and Mullertz as we reported previously (27).

Pharmacokinetic analysis. Male Sprague-Dawley rats (180-220 g) were divided into two groups, with each group injected intravenously with LK and $\mathrm{mPEG}_{20000}$-SC-LK (LK base dose of $25 \mathrm{mg} / \mathrm{kg}$ of body weight), respectively. Blood samples (200-300 $\mu \mathrm{l})$ at different time were collected and centrifuged prior to analysis. For the determination of LK content, serum samples were analyzed using LK ELISA assay kit (Mlbio, Shanghai, China) following directions. The results were demonstrated as mean values \pm SD. Pharmacokinetic parameters, including half-life $\left(\mathrm{t}_{1 / 2}\right)$, plasma peak concentration $\left(\mathrm{C}_{\max }\right)$, peak retention time $\left(\mathrm{T}_{\max }\right)$ and area under the curve (AUC) were calculated using a Pk solver 2.0 software.

\section{In-vivo evaluation in rats}

Anti-thrombotic effect with artery-vein bypass thrombosis model in rats. Anti-thrombotic activity of $\mathrm{mPEG}_{20000}-\mathrm{SC}-\mathrm{LK}$ was studied in a rat model of artery-vein bypass thrombosis $(28,29)$. Male Sprague-Dawley rats (230-280 g) were divided into three groups including negative control group, LK group and $\mathrm{mPEG}_{20000}-\mathrm{SC}-\mathrm{LK}$ group. The rats were anesthetized with an intravenous injection of pentobarbital sodium $(30 \mathrm{mg} / \mathrm{kg})$. A skin incision was made in the neck, and a segment of the left carotid artery was separated and clamped with an artery clamp. Then a catheter with a $2.0 \mathrm{~cm}$ long segment of silk was inserted into the left carotid artery from the proximal end, allowed for running along the vessels for $1.0 \mathrm{~cm}$, and then penetrated out from the distal end. Another end of carotid artery was tied to snip the thread, and the artery clamp was slowly loosened to restore the blood flow. Five min after the thrombus model were established, the LK and $\mathrm{mPEG}_{20000}$-SC-LK were injected intravenously via sublingual vein with the LK base dose of $25 \mathrm{mg} / \mathrm{kg}$ through $25 \mathrm{G}^{5 / 8}$ needles. Rats in negative control group were given an equal volume of normal saline. There were no side effects 
<smiles>COCCOCCOCCOCCOC(=O)ON1C(=O)CCC1=O</smiles>

Figure 1. PEGylated modification of LK by mPEG-SC. LK, Lumbrokinase.

such as skin wound or bleeding happened after the injection. Five hours after drug administration, the thrombus formed on silk suture was isolated and weighted. The inhibition ratio of thrombosis was calculated as follow equation. Inhibition ratio $=\left(\right.$ Weight $_{\text {control }}$-weight $\left._{\text {drug }}\right) /$ weight $_{\text {control }} \times 100 \%$.

Anti-thrombolic effect with $\mathrm{FeCl}_{3}$-induced carotid artery thrombosis model in rats. $\mathrm{FeCl}_{3}$-induced arterial thrombus formation in vivo was investigated as reported $(30,31)$, and the operating procedure was as described above. A 2x5 mm strip of filter paper saturated with $20 \% \mathrm{FeCl}_{3}$ solution was applied to the surface of the surgically exposed carotid artery for 10 min before being removed. The LK and $\mathrm{mPEG}_{20000}-\mathrm{SC}-\mathrm{LK}$ were then injected intravenously via sublingual vein with the LK base dose of $25 \mathrm{mg} / \mathrm{kg}$ through $25 \mathrm{G}^{5 / 8}$ needles just before and $15 \mathrm{~min}$ after removing the filter paper, respectively. Rats in negative control group were given equal volume of normal saline. Blood samples were taken from animals $3 \mathrm{~h}$ after the last drug injection, and centrifugated at 3,000 $\mathrm{g}$ for $15 \mathrm{~min}$ at $4^{\circ} \mathrm{C}$. The plasma $\mathrm{TXB}_{2}$ and $\mathrm{PGF}_{1 \alpha}$ concentrations were determined by ELISA, using the reagent set $\mathrm{TXB}_{2}$ express kit (Biosamite, Shanghai, China) and $\mathrm{PGF}_{1 \alpha}$ express kit (Biosamite). The plasma concentrations of t-PA were determined using a RAT tPA ELISA kit (Biosamite). The RAT PAI-1 ELISA kit (Biosamite) was used for detection of PAI-1 in plasma. All of the parameters were determined according to the manufacture's instructions.

Statistical analysis. Results were demonstrated as mean \pm SD. Statistical comparisons were performed to determine group differences through analysis of variance. Significant difference between two groups was evaluated by Student's t-test, and $\mathrm{p}<0.05$ is considered significant.

\section{Results}

Molecular weight determination of $M P E G_{20000}-S C-L K$. The molecular weight of the purified LK and $\mathrm{mPEG}_{20000}$-SC-LK were determined to be $24045.6 \mathrm{Da}$ (Fig. 2A, peak 1) and 44102.5 Da (Fig. 2B, peak 3) by MALDI-TOF mass spectrometry. The difference of molecular mass between LK and $\mathrm{mPEG}_{20000}$-SC-LK was $\sim 20 \mathrm{kDa}$, indicating that one molecular of PEG was linked to one molecular of LK.

Analysis by SDS-PAGE demonstrated a band at the molecular weight of $35-50 \mathrm{kDa}$ for $\mathrm{mPEG}_{20000}-\mathrm{SC}-\mathrm{LK}$ (Fig. 3, line 1), while that of LK (Fig. 3, line 2) was at around $24 \mathrm{kDa}$. This result was in good agreement with the result of MALDI-TOF.

Pharmacokinetics. Profiles of plasma concentration vs. time for $\mathrm{LK}$ and $\mathrm{mPEG}_{20000}$-SC-LK were shown in Fig. 4. As shown in Fig. 4 and Table I, LK was rapidly cleared from the plasma after $\mathrm{t}_{1 / 2}$ of $1.32 \mathrm{~h}$. Compared to LK, mPEG $_{20000}-\mathrm{SC}-\mathrm{LK}$ showed
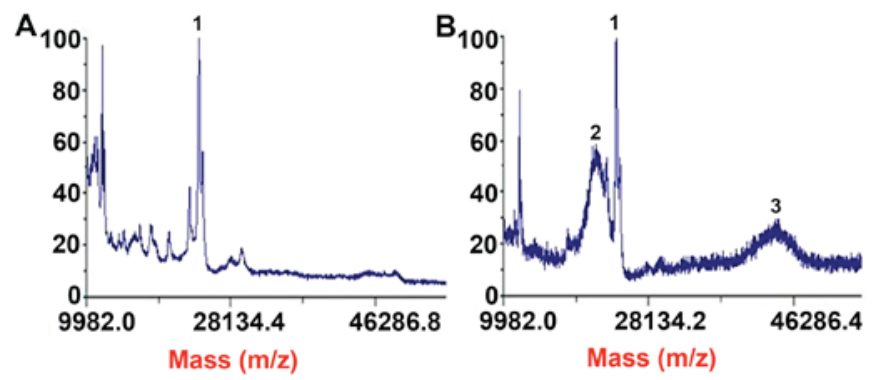

Figure 2. MALDI-TOF spectra of the purified LK (A) and $\mathrm{mPEG}_{20000}-\mathrm{SC}-\mathrm{LK}$ (B) In the figure, 1 was the peak of purified LK; 2 was the peak of residual $\mathrm{mPEG}_{20000}-\mathrm{SC}, 3$ was the peak of $\mathrm{mPEG}_{20000}-\mathrm{SC}-\mathrm{LK}$. LK, Lumbrokinase.

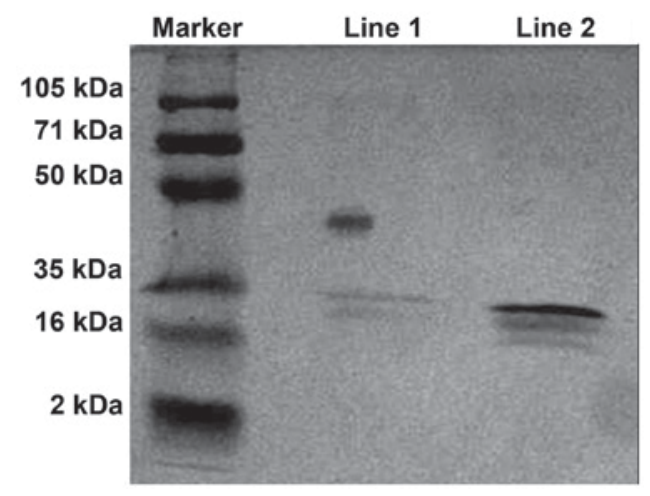

Figure 3. SDS-PAGE (10\%, w/v) gel of Coomasie staining. Line 1, $\mathrm{mPEG}_{20000}$-SC-LK; line 2, purified LK. LK, Lumbrokinase.

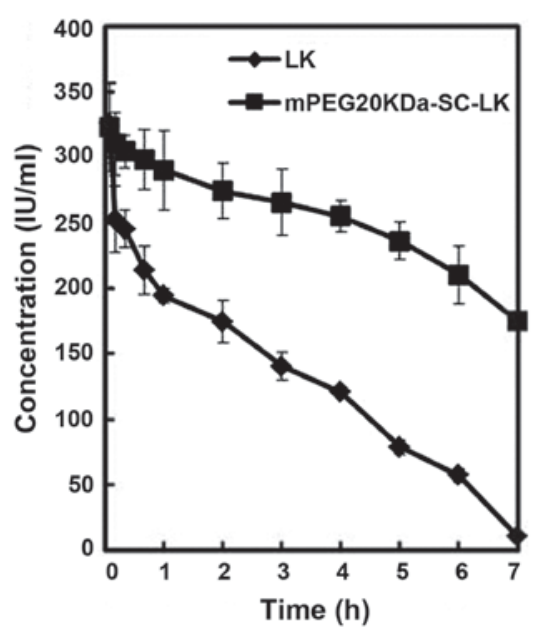

Figure 4. Mean plasma concentration-time curves of LK and $\mathrm{mPEG}_{20000}$-SC-LK. Blood clearance of the samples in rats following a single subcutaneous injection. The measurement was carried out using ELISA and each sample was measured for three times. LK, Lumbrokinase.

2.2-fold increase in $\mathrm{t}_{1 / 2}$. The $\mathrm{mPEG}_{20000}-\mathrm{SC}-\mathrm{LK}$ also displayed 3.7-fold decrease in CL. This revealed markedly prolonged serum presence of LK by PEGylation. Thus the results clearly indicated the potential of PEGylation to improve the pharmacokinetics of protein-based medicines.

\section{In-vivo evaluation}

Anti-thrombolic effect with artery-vein bypass thrombosis model in rats. In the model group, $1 \mathrm{~h}$ after embedding the 
Table I. Pharmacokinetic parameters of $\mathrm{LK}$ and $\mathrm{mPEG}_{20000^{-}}$ $\mathrm{SC}-\mathrm{LK}(\mathrm{n}=6$, mean $\pm \mathrm{SD})$.

\begin{tabular}{lcc}
\hline Parameters & LK & $\begin{array}{c}\mathrm{mPEG}_{20000^{-}} \\
\text {SC-LK }\end{array}$ \\
\hline MRT (h) & $1.90 \pm 0.75$ & $4.19 \pm 0.87$ \\
$\mathrm{~T}_{1 / 2}(\mathrm{~h})$ & $1.32 \pm 0.53$ & $2.90 \pm 0.39$ \\
$\mathrm{AUC}(\mathrm{IU} . \mathrm{h} / \mathrm{ml})$ & $607.86 \pm 101.23$ & $2,246.28 \pm 586.28$ \\
$\mathrm{CL}(\mathrm{ml} / \mathrm{h} / \mathrm{kg})$ & $1.36 \pm 0.78$ & $0.37 \pm 0.11$ \\
Vss $(\mathrm{ml} / \mathrm{kg})$ & $2.58 \pm 0.69$ & $1.54 \pm 0.86$ \\
\hline
\end{tabular}

MRT, mean residence time; $\mathrm{T}_{1 / 2}$, half-life; AUC, area under drug concentration vs. time curve; $\mathrm{Cl}$, clearance over bioavailability; Vss, distribution volume at steady state.

Table II. Effects of LK and $\mathrm{mPEG}_{20000}-\mathrm{SC}-\mathrm{LK}$ on artery-vein bypass thrombosis $(n=6$, mean $\pm S D)$.

\begin{tabular}{lcc}
\hline Group & $\begin{array}{c}\text { Thrombus } \\
\text { mass }(\mathrm{mg})\end{array}$ & $\begin{array}{c}\text { Inhibition } \\
\text { ratio }(\%)\end{array}$ \\
\hline Negative control & $16.34 \pm 1.25$ & - \\
LK & $5.47 \pm 1.81^{\mathrm{a}}$ & 13.72 \\
mPEG $_{20000^{-S C}-\mathrm{LK}}$ & $3.35 \pm 1.53^{\mathrm{a}, \mathrm{b}}$ & $47.16^{\mathrm{b}}$ \\
\hline
\end{tabular}

${ }^{\text {a }} \mathrm{P}<0.05$ compared with negative control; ${ }^{\text {b }} \mathrm{P}<0.05$ compared with $\mathrm{LK}$ group. LK, Lumbrokinase.

silk, the carotid artery became dark red, thrombosis formed, and the size of it was gradually increased. Injection of LK and $\mathrm{mPEG}_{20000}$-SC-LK inhibited the thrombus formation, with $\mathrm{mPEG}_{20000}-\mathrm{SC}-\mathrm{LK}$ more effective than LK (Table II). In the $\mathrm{mPEG}_{20000}$-SC-LK group, $47.16 \%$ inhibition of thrombosis was observed compared to $13.72 \%$ in LK group, indicating that $\mathrm{mPEG}_{20000}-\mathrm{SC}-\mathrm{LK}$ had stronger anti-thrombolic effect than native $\mathrm{LK}$.

Anti-thrombolic effect in $\mathrm{FeCl}_{3}$-induced carotid artery thrombosis model in rats. Completely occlusive carotid artery thrombosis was well established in rats, as presented in Fig. 5 After the injection of LK and $\mathrm{mPEG}_{20000}-\mathrm{SC}-\mathrm{LK}, \mathrm{TXB}_{2}$ concentrations in both groups decreased compared with model group $(\mathrm{P}<0.05)$, and the $\mathrm{TXB}_{2}$ content in $\mathrm{mPEG}_{20000}-\mathrm{SC}-\mathrm{LK}$ group decreased more than that in LK group $(\mathrm{P}<0.05)$ (Fig. 6). The content of $\mathrm{PGF}_{1 \alpha}$ was higher in $\mathrm{LK}$ and $\mathrm{mPEG}_{2000}-\mathrm{SC}-\mathrm{LK}$ groups when compared with the model group $(\mathrm{P}<0.05)$, and the $\mathrm{PGF}_{1 \alpha}$ content in $\mathrm{mPEG}_{20000}-\mathrm{SC}-\mathrm{LK}$ group was higher than that in LK group $(\mathrm{P}<0.05)$ (Fig. 6). In the model group, ratio of t-PA and t-PA/PAI-1 activity was lower than the normal group, while the value of PAI-1 was increased in model group when compared with the normal group (Fig. 7). After administration of $\mathrm{LK}$ and $\mathrm{mPEG}_{20000}-\mathrm{SC}-\mathrm{LK}$, the activity of t-PA and t-PA/PAI-1 ratio were higher than the model group $(\mathrm{P}<0.05)$, while the activity of PAI-1 had no change. When compared with LK group, the activity of t-PA and t-PA/PAI-1 ratio was higher in $\mathrm{mPEG}_{20000}$-SC-LK group $(\mathrm{P}<0.05)$.

\section{Discussion}

Present study focused on development and evaluation of a long-acting anti-thrombosis agent through PEGylation of LK. PEGylated LK was successfully modified with $\mathrm{mPEG}_{20000}-\mathrm{SC}$ in optimal condition as we reported before (25). As the effective molecular weight of crude LK was around $24 \mathrm{kDa}$, the theoretical molecular weight of PEGylated LK was around $44 \mathrm{kDa}$. Both the SDS-PAGE and MALDI-TOF results were consistent with our expectation, suggesting that LK was successfully modified with $\mathrm{mPEG}_{20000}-\mathrm{SC}$. The in vitro fibrinolytic activity of the PEGylated products was lower than that of purified LK although the calues were not significantly different. Despite the trend for PEGylation to decrease in vitro fibrinolytic activity, this may not influence in vivo activity because of the longer circulation half-life of PEG modified LK.

Multiple approaches have been devised to extend the half-life and increase activity of anti-thrombotic agents in the bloodstream, such as polymer coating and the use of drug carriers. The most commonly used approach to prolong the half-life of anti-thrombotic agents involves conjugation of drugs with PEG. PEG chains form a hydrated shell that enhances drug solubility and limits renal filtration, proteolytic degradation, and immunogenicity (1). In practice, it has been reported that $\mathrm{PEG}_{20000}$-IFN and $\mathrm{PEG}_{40000}$-IFN significantly prolonged serum half-life and lowered the renal clearance rate $(14,23)$. In our study, the serum activity of $\mathrm{mPEG}_{20000}$-SC-LK showed 2.2-fold increase in $\mathrm{t}_{1 / 2}$ than the native $\mathrm{LK}$, and the $\mathrm{mPEG}_{20000}-\mathrm{SC}$-LK displayed 3.7-fold decrease in CL. The reduction ranges of $\mathrm{mPEG}_{20000}-\mathrm{SC}-\mathrm{LK}$ were much smaller than those of native LK. Seven $h$ after the injection of native LK, the serum LK concentration was decreased below $10 \mathrm{IU} / \mathrm{ml}$, while the serum $\mathrm{mPEG}_{20000}$-SC-LK concentration was remained above $170 \mathrm{IU} / \mathrm{ml}$, indicating that $\mathrm{mPEG}_{20000}$-SC-LK had long-circulating effects and prolonged biological half-life and residence time in vivo. PEGylation increased the size and molecular weight of LK and improved its pharmacokinetics by protecting from enzymatic degradation, prolonging circulation time and reducing renal clearance. PEG polymer linked to LK, may creates a bulky hydrophilic shield which could efficiently mask the conjugated LK from enzymatic digestion.

LK extracted from the earthworm has been used to treat stroke and cardiovascular diseases $(32,33)$. Recent studies (34) have shown that the fibrinolytic enzymes could dissolve blood fibrin clots and inhibit activation and aggregation of platelets. However, most studies mainly focused on the oral preparation of these enzymes. This is the first report to systematically evaluate the ant-thrombotic effect of PEGylated injection form of LK in animal model. Artery-vein bypass thrombosis animal model was widely used in evaluating properties of anti-thrombotic preparations. In our experiment, $\mathrm{mPEG}_{20000}$-SC-LK showed nearly 3.5 -fold increase in the inhibition ratio of thrombosis effect compared with the native one in this rat model.

$\mathrm{FeCl}_{3}$-induced carotid artery thrombosis model is another typical model to eveluate an anti-thombosis agent. To investigate changes of $\mathrm{TXB}_{2}, \mathrm{PGF}_{1 \alpha}$, t-PA and t-PA/PAI-1 ratio, thrombi were induced by topical ferric chloride in our experiment. $\mathrm{TXB}_{2}$ as the end product of the metabolism of 


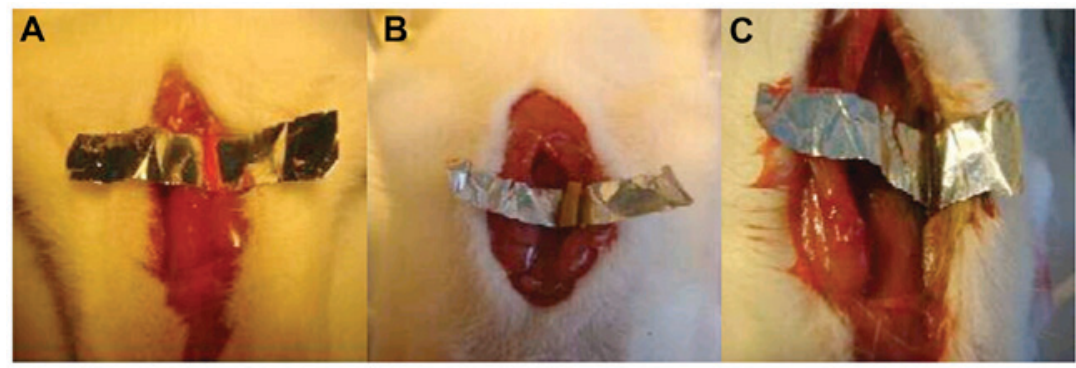

Figure 5. Induction of vascular injury in rat carotid artery. (A) Isolated the left carotid artery; (B) one piece of $2 \times 5 \mathrm{~mm}$ filter paper saturated with $20 \% \mathrm{FeCl}_{3}$ was applied wo surface of surgically exposed left carotid artery for 10 min. (C) Formation of thrombus.
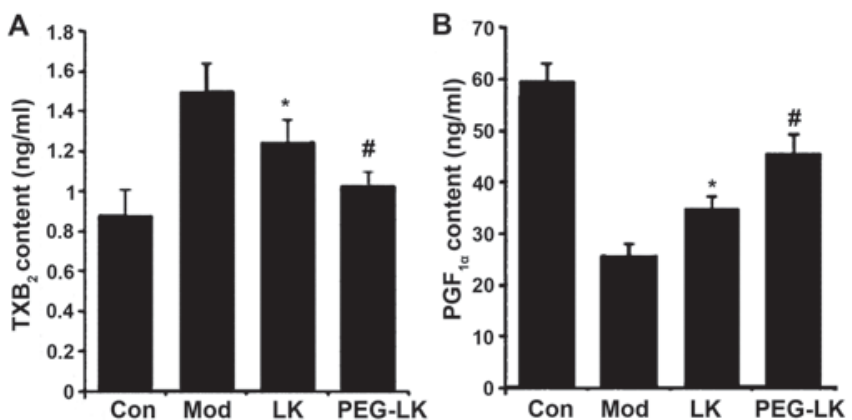

Figure 6. Comparison of content of $\mathrm{TXB}_{2}(\mathrm{~A})$ and $\mathrm{PGF}_{1 \alpha}(\mathrm{B})$ in rat plasma in different groups. Each value represents the mean $\pm \mathrm{SD}$ for three determinations. ${ }^{\mathrm{P}}<0.05$, compared with model group; ${ }^{*} \mathrm{P}<0.05$, compared with $\mathrm{LK}$ group. LK, Lumbrokinase.
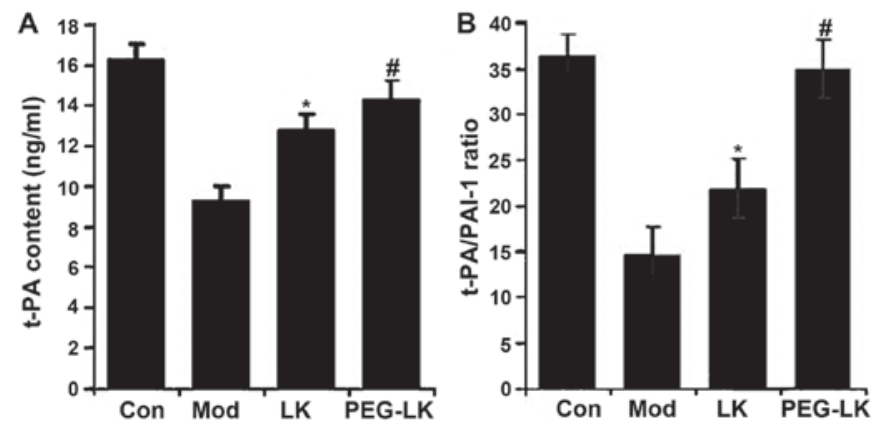

Figure 7. Comparison of content of t-PA (A) and t-PA/PAI-1 ratio (B) in rat plasma in different groups. Each value represents the mean \pm SD for three determinations. ${ }^{*} \mathrm{P}<0.05$, compared with model group; ${ }^{*} \mathrm{P}<0.05$, compared with LK group. t-PA, tissue plasminogen activator; LK, Lumbrokinase.

$\mathrm{XA}_{2}(35,36)$, has an important role in the promotion of platelet aggregation and contraction of blood vessels. It has been reported that patients with atherosclerosis showed high plasma $\mathrm{TXB}_{2}$ values and low $\mathrm{PGF}_{1 \alpha}$ content. After taking 2 weeks of $\mathrm{LK}$, the plasma level of $\mathrm{TXB}_{2}$ significantly decreased and $\mathrm{PGF}_{1 \alpha}$ level significantly increased in patients, suggesting that LK has a strong inhibitory effect on platelet aggregation. After the injection of LK and $\mathrm{mPEG}_{20000}-\mathrm{SC}$-LK, we saw that the $\mathrm{TXB}_{2}$ concentrations decreased compared to the model group, and the $\mathrm{TXB}_{2}$ content in $\mathrm{mPEG}_{20000}$-SC-LK group decreased more than that of LK group. The content of $\mathrm{PGF}_{1 \alpha}$ was higher in both $\mathrm{LK}$ and $\mathrm{mPEG}_{20000}-\mathrm{SC}-\mathrm{LK}$ groups when compared with the model group, and the $\mathrm{PGF}_{1 \alpha}$ content in $\mathrm{mPEG}_{20000}$-SC-LK group was increased greater than that in LK group.
Endogenously mediated fibrinolysis is initiated by t-PA and u-PA, the enzymes convert plasminogen to the fibrinolytic protease plasmin (37). T-PA and PAI are a pair of biological regulatory factors which are of great significance to the function of fibrinolytic system. T-PA can specifically combine with fibrin in plasma, possessing selective thrombolysis effect. PAI as a rapid inhibitor can inactivate t-PA by combining with it. It plays a decisive role in fibrinolytic system by inhibiting the role of anti-thrombosis effect. According to the literature (38), the t-PA/PAI ratio was often used as an index of anti-thrombosis. This study showed that in $\mathrm{FeCl}_{3}$-indeced thrombosis rat model, the content of $\mathrm{TXB}_{2}$ was increased, whereas PGF ${ }_{1 \alpha}$ content, t-PA content and $t$-PA/PAI ratio were all decreased in the model group. This is because as endothelial damage was occurred due to vascular endothelium, the platelet and coagulation system was activated and the anti-coagulant protein in the blood was consumed, leading to decreased anti-coagulant activity. Meanwhile, because of the formation of thrombus, the t-PA in the blood combined to the thrombus location decreased the activity of t-PA. As an anti-thrombosis agent, LK can directly dissolve fibrin or indirectly dissolve fibrin by activating profibrinolysin. Thus, LK can eventually reduce thrombotic diseases in patients with PAI and activate t-PA, resulting in increased fibrinolysis. After administration of the drugs, t-PA and t-PA/PAI ratio was increased, and the rising range of $\mathrm{mPEG}_{20000}-\mathrm{SC}-\mathrm{LK}$ was greater than the native LK group. The lower in vitro potencies of the PEGylated LK relative to those of the native LK may be due to steric shielding of the protein by the PEG polymer with its comb-like structure (39). But when it comed to in vivo situation, PEGylated LK presented better anti-thrombosis efficacy than the native one. Because PEGylation is able to enhance drug efficacy by reducing its clearance either through glomeular filtration or through proteolytic degradation.

Vascular thrombotic disease is a serious threat to human health which is the main cause of human disability and death. According to the results of our research, it demonstrated that $\mathrm{mPEG}_{20000}$-SC-LK exhibited greater anti-thrombosis effect in both artery-vein bypass thrombosis and $\mathrm{FeCl}_{3}$-induced carotid artery thrombosis models than native LK. It could effectively improve the clinical symptoms of patients, reduce morbidity and morbidity, and it is an ideal drug to treat vascular thrombotic disease in clinical, such as myocardial infarction combined high blood fibrinogen, high stick sluggish blood disease, retinal vein occlusion, cerebrovascular disease, 
infarction, and so on. Therefore, it is a potential anti-thrombotic agent for long-acting treatment of the thrombus diseases.

Present study showed that mPEG modified LK have prolonged half-life and strong fibrinolytic and thrombolytic activities in vivo. These results indicate that the PEGylated LK is a novel anti-thrombosis agent for the treatment of thrombosis diseases in clinic. These results can provide the foundation of the research of injective LK in the future study.

\section{Acknowledgements}

This study was supported by research grants from the National Natural Science Foundation of China (no. 81373342).

\section{References}

1. Greineder CF, Howard MD, Carnemolla R, Cines DB and Muzykantov VR: Advanced drug delivery systems for antithrombotic agents. Blood 122: 1565-1575, 2013.

2. Cong YW, Liu YM and Chen JP: The advance of lumbrokinase. Chin J Biochem Pharm 21: 159-162, 2001.

3. Wang F, Wang C, Li M, Gui LL, Zhang JP and Chang WR: Purification, characterization and crystallization of a group of earthworm fibrinolytic enzymes from Eisenia fetida. Biotechnolo Lett 25: 1105-1109, 2003.

4. Wang C, Wang F, Li M, Tang Y, Zhang JP, Gui LL, An XM and Chang WR: Structural basis for broad substrate specificity of earthworm fibrinolytic enzyme component A. Biochem Bioph Res Commun 325: 877-882, 2004.

5. Vernooij MW, Haag MD, van der Lugt A, Hofman A, Krestin GP, Stricker BH and Breteler MM: Use of antithrombotic drugs and the presence of cerebral microbleeds: The rotterdam scan study. Arch Neurol 66: 714-720, 2009.

6. Delaney JA, Opatrny L, Brophy JM and Suissa S: Drug drug interactions between antithrombotic medications and the risk of gastrointestinal bleeding. CMAJ 177: 347-351, 2007.

7. Hrženjak T, Popović M, Božić T, Grdisa M, Kobrehel D and Tiška-Rudman L: Fibrinolytic and anticoagulative activities from the earthworm Eisenia foetida. Comp Biochem Physiol B Biochem Mol Biol 119: 825-832, 1998.

8. Mihara H, Sumi H, Yoneta T, Mizumoto H, Ikeda R, Seiki M and Maruyama M: A novel fibrinolytic enzyme extracted from the earthworm, Lumbricus rubellus. Jap J Physiol 41: 461-472, 1991.

9. Nakajima N, Sugimoto M, Ishihara K, Nakamura K and Hamada H: Further characterization of earthworm serine proteases: Cleavage specificity against peptide substrates and on autolysis. Biosc Biotechnol Biochem 63: 2031-2033, 1999.

10. Jin G, Jin M, Jin Z, Gao Z and Yin X: Docetaxel-loaded PEG-albumin nanoparticles with improved antitumor efficiency against non-small cell lung cancer. Oncol Rep 36: 871-876, 2016.

11. Tsui SM, Lam WM, Lam TL, Chong HC, So PK, Kwok SY, Arnold S, Cheng PN, Wheatley DN, Lo WH and Leung YC: Pegylated derivatives of recombinant human arginase (rhArg1) for sustained in vivo activity in cancer therapy: Preparation, characterization and analysis of their pharmacodynamics in vivo and in vitro and action upon hepatocellular carcinoma cell (HCC). Cancer Cell Int 9: 9, 2009.

12. Milla P, Dosio F and Cattel L: PEGylation of proteins and liposomes: A powerful and flexible strategy to improve the drug delivery. Curr Drug Metab 13: 105-119, 2012.

13. Kajihara J, Shibata K, Nakano Y, Nishimuro S and Kato K: Physicochemical characterization of PEG-PPG conjugated human urokinase. Biochim Biophys Acta 1199: 202-208, 1994.

14. Jo YW, Yu SY, Lee SH, Kim BM, Kang SH, Yoo M, Choi EC and Lee KC: Long-acting interferon-alpha 2 a modified with a trimer-structured polyethylene glycol: Preparation, in vitro bioactivity, in vivo stability and pharmacokinetics. Int J Pharm 309: 87-93, 2006.

15. Veronese FM: Peptide and protein PEGylation: A review of problems and solutions. Biomaterials 22: 405-417, 2001.

16. Roberts MJ, Bentley MD and Harris JM: Chemistry for peptide and protein PEGylation. Adv Drug Deliver Rev 54: 459-476, 2002.

17. Veronese FM and Pasut G: PEGylation, successful approach to drug delivery. Drug Discov Today 10: 1451-1458, 2005.
18. Berger H Jr and Pizzo SV: Preparation of polyethylene glycol-tissue plasminogen activator adducts that retain functional activity: Characteristics and behavior in three animal species. Blood 71: 1641-1647, 1988.

19. Rajagopalan S, Gonias SL and Pizzo SV: A nonantigenic covalent streptokinase-polyethylene glycol complex with plasminogen activator function. J Clin Invest 75: 413-419, 1985.

20. Sakuragawa N, Shimizu K, Kondo K, Kondo S and Niwa M: Studies on the effect of PEG-modified urokinase on coagulation-fibrinolysis using beagles. Thromb Res 41: 627-635, 1986.

21. Moreadith RW and Collen D: Clinical development of PEGylated recombinant staphylokinase (PEG-Sak) for bolus thrombolytic treatment of patients with acute myocardial infarction. Adv Drug Deliv Rev 55: 1337-1345, 2003.

22. Jin G, Jin M, Yin X, Jin Z, Chen L and Gao Z: A comparative study on the effect of docetaxel-albumin nanoparticles and docetaxel-loaded PEG-albumin nanoparticles against non-small cell lung cancer. Int J Oncol 47: 1945-1953, 2015.

23. Podobnik B, Helk B, Smilović V, Škrajnar S, Fidler K, Jevševar S, Godwin A and Williams P: Conjugation of PolyPEG to interferon alpha extends serum half-life while maintaining low viscosity of the conjugate. Bioconjug Chem 26: 452-459, 2015.

24. Pasut $G$ and Veronese FM: State of the art in PEGylation: The great versatility achieved after forty years of research. J Control Release 161: 461-472, 2012.

25. Jin M, Chen W, Huang W, Rong L and Gao Z: Preparation of pegylated lumbrokinase and an evaluation of its thrombolytic activity both in vitro and in vivo. Acta Pharm Sinica B 3: 123-129, 2013.

26. Park JB, Kwon YM, Lee TY, Brim R, Ko MC, Sunahara RK, Woods JH and Yang VC: PEGylation of bacterial cocaine esterase for protection against protease digestion and immunogenicity. J Control Release 142: 174-179, 2010.

27. Astrup T and Mullertz S: The fibrin plate method for estimating fibrinolytic activity. Arch Biochem Biophys 40: 346-351, 1952.

28. Maksimenko AV, Tishchenko EG and Golubykh VL: Antithrombotic activity of the superoxide dismutase-chondroitin sulfate complexes in a rat model of arterial injury. Cardiovasc Drug Ther 13: 479-484, 1999.

29. Wu B and Xu J: Antithrombotic effect of a novel protein from Fusarium sp. CPCC 480097 in a rat model of artery-vein bypass thrombosis. Pharm Biol 50: 866-870, 2012.

30. Kurz KD, Main BW and Sandusky GE: Rat model of arterial thrombosis induced by ferric chloride. Thromb Res 60: 269-280, 1990.

31. Zhao Y, Chu X, Pang XB, Wang SH and Du GH: Antithrombotic effects of the effective components group of Xiaoshuantongluo formula in vivo and in vitro. Chin J Nat Med 13: 99-107, 2015.

32. Jin $\mathrm{L}$, Jin $\mathrm{H}$, Zhang $\mathrm{G}$ and $\mathrm{Xu} \mathrm{G}$ : Changes in coagulation and tissue plasminogen activator after the treatment of cerebral infarction with lumbrokinase. Clin Hemorheol Microcirc 23: 213-218, 2000.

33. Ji H, Wang L, Bi H, Sun L, Cai B, Wang Y, Zhao J and Du Z: Mechanisms of lumbrokinase in protection of cerebral ischemia. Eu J Pharmacol 590: 281-289, 2008.

34. Dong GQ, Yuan XL, Shan YJ, Zhao ZH, Chen JP and Cong YW: Molecular cloning and characterization of cDNA encoding fibrinolytic enzyme-3 from earthworm Eisenia foetida. Acta Bioch Biop Sin (Shanghai) 36: 303-308, 2004.

35. Tohgi H, Tamura K, Kimura B, Kimura M and Suzuki H: Individual variation in platelet aggregability and serum thromboxane B2 concentrations after low-dose aspirin. Stroke 19: 700-703, 1988.

36. Kim HS, Zhang YH, Fang LH, Yun YP and Lee HK: Effects of tetrandrine and fangchinoline on human platelet aggregation and thromboxane B2 formation. J Ethnopharmacol 66: 241-246, 1999.

37. Collen D and Lijnen HR: Basic and clinical aspects of fibrinolysis and thrombolysis. Blood 78: 3114-3124, 1991.

38. Wang KY, Tull L, Cooper E, Wang N and Liu D: Recombinant protein production of earthworm lumbrokinase for potential antithrombotic application. Evid Based Compl Alternat Med 2013: 783971, 2013.

39. Collen D, Sinnaeve P, Demarsin E, Moreau H, De Maeyer M, Jespers L, Laroche Y and Van de Werf F: Polyethylene glycol-derivatized cysteine-substitution variants of recombinant staphylokinase for single-bolus treatment of acute myocardial infarction. Circulation 102: 1766-1772, 2000. 